\title{
Estimation of external infection pressure and salmon-louse population growth rate in Faroese salmon farms
}

\author{
Tróndur J. Kragesteen ${ }^{1,2, *}$, Knud Simonsen ${ }^{1,3}{ }^{\text {, André W. Visser }}{ }^{2}$, Ken H. Andersen ${ }^{2}$ \\ ${ }^{1}$ Fiskaaling - Aquaculture Research Station of the Faroes, við Áir, 430 Hvalvík, Faroe Islands \\ ${ }^{2}$ VKR Centre for Ocean Life, National Institute of Aquatic Resources, Technical University of Denmark, Bygning 202, \\ 2800 Kgs. Lyngby, Denmark \\ ${ }^{3}$ Frøðskaparsetur Føroya - Universtity of the Faroe Islands, J. C. Svabos gøta 14, 100 Tórshavn, Faroe Islands
}

\begin{abstract}
Managing salmon louse Lepeophtheirus salmonis outbreaks is a crucial part of salmon aquaculture in sea cages. Treatment management strategies can be optimized with the aid of salmon-louse population dynamic models. These models, however, need to be calibrated and validated with biologically meaningful parameters. Here, based on a time-series of lice data, we estimated 2 essential model parameters: the external infection pressure and the salmon-louse population growth rate for each active salmon farm site in the period 2011 to 2018 in the Faroe Islands. External infection pressure was found to vary between farm sites and ranged on average from 0.002 to 0.1 lice salmon ${ }^{-1} \mathrm{~d}^{-1}$. Further, external infection was significantly correlated with the total number of gravid lice in the Faroese farm network. Salmon-louse population growth rates were found to vary between farm sites and ranged on average from 1.7 to $5.4 \% \mathrm{~d}^{-1}$. These model parameter estimates are crucial in developing a salmon-louse population dynamic model for the Faroe Islands, and the method to estimate these parameters may be applicable in other aquaculture regions.
\end{abstract}

KEY WORDS: Salmon aquaculture $\cdot$ Salmon lice $\cdot$ Modelling

\section{INTRODUCTION}

Managing sea lice on a regional or national scale is a crucial part of modern sea-based salmon aquaculture. In the northern hemisphere, the most important sea louse impacting salmon aquaculture is the ectoparasite Lepeophtheirus salmonis, also known as the salmon louse. The salmon louse is a naturally occurring parasite on salmonid fish and feeds on the mucus, skin and blood of its host (Pike \& Wadsworth 1999). At high densities, lice can cause physical damage to their host and expose them to secondary infections, as well as causing stress and osmotic regulatory imbalance (Pike \& Wadsworth 1999).

\footnotetext{
${ }^{*}$ Corresponding author: trondurk@fiskaaling.fo
}

As the salmon farming industry has grown, so has the number of salmon-louse hosts providing favourable conditions for the parasite. At sufficiently high host densities, salmon lice can develop into an epidemic (Frazer et al. 2012), negatively affecting both salmon farms and wild salmonid stocks (Krkošek et al. 2006, Kristoffersen et al. 2018). Understanding the dynamics of louse population growth and outbreaks and how lice disperse has obvious potential to reduce treatment frequency and fish mortality in both farmed and wild salmon stocks, increasing economic output and decreasing ecological impact.

Numerical models describing salmon-louse population growth have been developed based on Anderson

() The authors 2021. Open Access under Creative Commons by Attribution Licence. Use, distribution and reproduction are unrestricted. Authors and original publication must be credited. 
\& May (1979) type host-parasite models (Krkošek et al. 2010, Frazer et al. 2012) and delayed stage structured models (Revie et al. 2005, Stien et al. 2005, Robbins et al. 2010, Gettinby et al. 2011, Adams et al. 2015, Kragesteen et al. 2019). Louse population growth rate is determined by 2 processes: external infection and internal infection. The external infection pressure is determined by lice arriving from other salmon farms and wild salmonid stocks. The internal infection pressure is determined by the production of lice on the farm. If internal infection is high enough, it will eventually lead to an exponentially growing salmon lice population. In the initial phase of salmon production, the external infection pressure is the dominating process of the population growth rate (Kristoffersen et al. 2014). Internal infection becomes the dominating process as the lice population increases (Krkošek et al. 2010).

External infection pressure has been estimated using sentinel cages in Norway, Scotland and Iceland (Bjørn et al. 2011, Pert et al. 2014, Sandvik et al. 2016, Karbowski et al. 2019). A sentinel cage is typically deployed 2-3 wk at a time over a period of months, and for each deployment lice are recorded. External infection pressure reported in these studies was found to vary significantly depending on the level of gravid lice in the area. Bjørn et al. (2011) found the external infection to be up to 2.3 lice salmon $^{-1}$ in the Romsdalsfjord system, Norway, with a $14 \mathrm{~d}$ deployment time. Sandvik et al. (2016) found up to 20 lice salmon ${ }^{-1}$ in Hardangerfjord, Norway, with a 14-21 d deployment time, and Pert et al. (2014) found close to 15 lice salmon ${ }^{-1}$ in Loch Shieldaig, Scotland, with a $7 \mathrm{~d}$ deployment time. In Arnarfjörður, Iceland, which only contained 2 salmon farms, Karbowski et al. (2019) found only 0.022 lice salmon $^{-1}$ when sampling for $\sim 21 \mathrm{~d}$.

Salmon-louse population growth rates have been reported for salmon farms in the Broughton Archipelago, Canada, and the Faroe Islands (Krkošek et al. 2010, Patursson et al. 2017). These estimates assume exponential growth, and Krkošek et al. (2010) reported 2 farms having 0.9 and $4.8 \% \mathrm{~d}^{-1}$, while Patursson et al. (2017) reported growth rates to range from 0.9 to $4.1 \% \mathrm{~d}^{-1}$ for several Faroese farms.

Here, we describe the general development of salmon lice abundance in the Faroe Islands from 2011 to 2018 based on an extensive time-series of sea lice counts. Further, we estimated external infection pressure and salmon-louse population growth rate on a per-farm basis using an alternative approach described herein. These parameter estimates are essential for the development of salmon-louse population dynamic models, which can aid in salmon lice management strategies.

\section{MATERIALS AND METHODS}

\subsection{Lice data and salmon numbers}

Lice data are based on the Faroese lice count program, which started in 2009, where the Faroese government mandated farmers to count lice every $14 \mathrm{~d}$ from 1 May to 31 December and once a month from 1 January to 30 April. However, lice counts were not performed on all farms until after 2012. From 2009 to 2016, a minimum of 10 fish were counted from 4 cages. The farmer chose 2 cages; the first cage was the first stocked cage, and the second cage was estimated to have the highest sea lice load, based on prior experience. The 2 other cages were chosen at random between cages that had not been counted previously. After 2016, a minimum of 10 fish were counted for all cages at each farm site every $14 \mathrm{~d}$ throughout the entire year (Faroese Ministry of Foreign Affairs and Trade 2016). In 2011, counting was not performed at 3 farms, and at 3 farms, lice counts started 3-6 mo into the year. In addition, daily salmon numbers for each farm site were provided by the Faroese aquaculture companies for the period between 2011 and 2018.

Both Lepeophtheirus salmonis and Caligus elongatus have been recorded; however, we will exclusively focus on the salmon louse as they have by far the largest economic impact on the salmon industry (Boxaspen 2006). The life cycle of L. salmonis consists of 8 stages (Schram 1993, Hamre et al. 2013). Non-feeding planktonic nauplii larvae hatch from gravid female egg strings and moult into nauplius II, and subsequently, into the third, and infective, stage, as a copepodite. After attachment, copepodites moult into immobile chalimus I and start feeding. The chalimus phase consists of 2 stages (chalimus I and II), where the latter moults into the first mobile pre-adult stage. After the pre-adult stages (pre-adult I and II), the louse moults into the adult and final stage.

Salmon-louse counts categorise these life stages into 3 groups: immobile (chalimus I and II), mobile and gravid female. Lepeophtheirus salmonis and C. elongatus are not distinguished from each other in the immobile group; these counts were therefore discarded and only mobile and gravid female lice were considered in this study. Mobile lice counts include the pre-adult stages (male and female) and adult male stage, while gravid lice only include adult gravid females. 


\subsection{Treatments}

Treatment data were gathered from the active Faroese farming companies from 2011 to 2018. There have been several kinds of treatments performed, which here are organized into 3 groups: medical oral (SLICE and Diflubenzuron), medicinal bath (hydrogen peroxide, Salmosan, Alpbamax, Betamax, Pyretroid and Azametiphos) and mechanical (freshwater bath, hydrolicer, optilicer, termolicer or flushing). A 'treatment event' was defined as a given kind of treatment performed at a given farm which had not been performed within the previous $7 \mathrm{~d}$. Number of treated cages was not resolved.

\subsection{Seawater temperature}

Seawater temperature was measured by the Faroe Marine Research Institute (www.envofar.fo). Seawater temperature is measured at $3 \mathrm{~m}$ depth at Oyrargjógv $\left(62^{\circ} 07^{\prime} \mathrm{N}, 7^{\circ} 10^{\prime} \mathrm{W}\right)$, which is located in a tidally well-mixed strait, and thus representative of a relative large geographical region (Fig. 1).

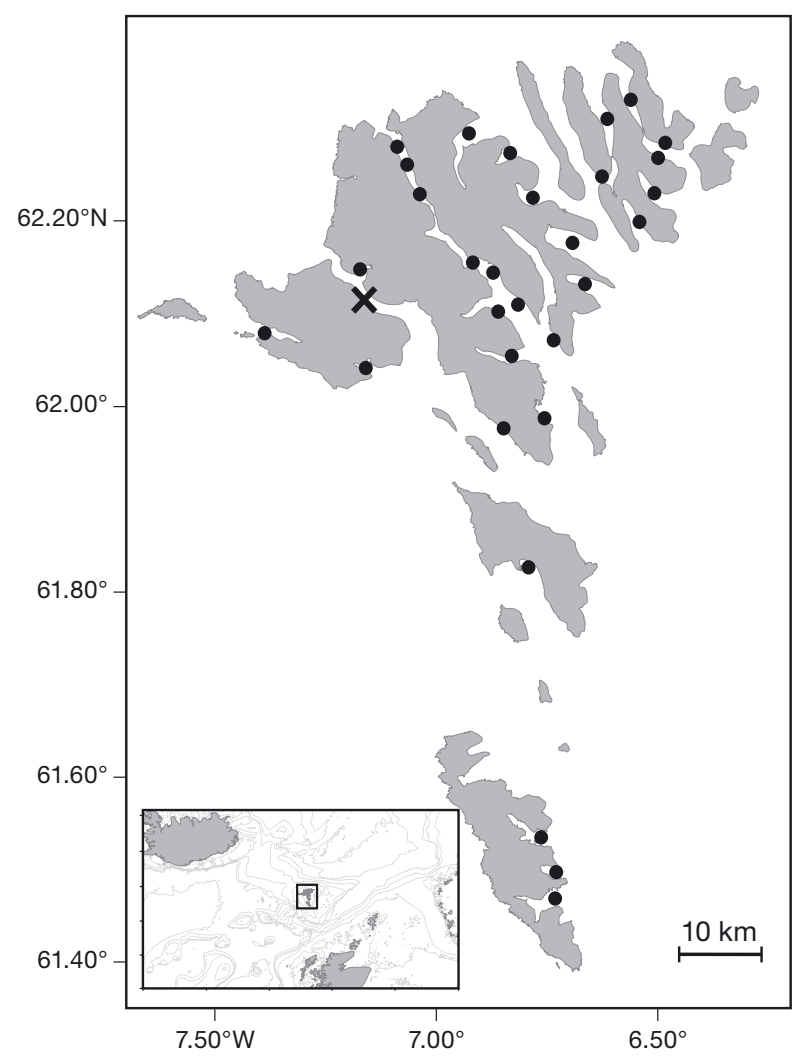

Fig. 1. Faroese farm locations (black circles) and location of temperature measurements (black cross)

\subsection{Calculating total lice numbers}

The total number of gravid and mobile lice was estimated for each farm $i$ by linear interpolation between the days of the counts to obtain the daily values $l_{i}(t)$. Using the number of salmon in each farm per day $F_{i}(t)$, the total number of lice in the region on a given day $t$ is obtained from:

$$
L_{\mathrm{tot}}(t)=\sum_{i=1}^{n} 1_{i}(t) F_{i}(t)
$$

where $n$ is the number of farms in the system. A total of 30 farms were investigated (Fig. 1).

\subsection{The salmon-louse model}

To estimate the external infection pressure and salmon-louse population growth rate, we used a series of delay differential equations (Revie et al. 2005):

$$
\frac{\mathrm{d} \rho_{1}(t)}{\mathrm{d} t}=\beta(t)-\beta\left(t-t_{1}\right) \mathrm{e}^{-\mu_{1} t_{1}}-\mu_{1} \rho_{1}(t)
$$

$$
\frac{\mathrm{d} \rho_{2}(t)}{\mathrm{d} t}=\beta\left(t-t_{1}\right) \mathrm{e}^{-\mu_{1} t_{1}}-\beta\left(t-t_{1}-t_{2}\right) \mathrm{e}^{-\mu_{1} t_{1}-\mu_{2} t_{2}}-\mu_{2} \rho_{2}(t)
$$

$\frac{\mathrm{d} \rho_{3}(t)}{\mathrm{d} t}=\beta\left(t-t_{1}-t_{2}\right) \mathrm{e}^{-\mu_{1} t_{1}-\mu_{2} t_{2}}-\beta\left(t-t_{1}-t_{2}-t_{3}\right) \mathrm{e}^{-\mu_{1} t_{1}-\mu_{2} t_{2}-\mu_{3} t_{3}}-\mu_{3} \rho_{3}(t)$

$$
\frac{\mathrm{d} \rho_{4}(t)}{\mathrm{d} t}=\beta\left(t-t_{1}-t_{2}-t_{3}\right) \mathrm{e}^{-\mu_{1} t_{1}-\mu_{2} t_{2}-\mu_{3} t_{3}}-\mu_{4} \rho_{4}(t)
$$

where $\rho_{1-4}$ represent the male and female lice at the chalimus, pre-adult, adult and sexually mature stages, respectively, and $\mu_{1-4}$ and $t_{1-4}$ represent mortality and development times, respectively, at the same stages. The amount of attached larvae $\beta(t)$ is defined in Kragesteen et al. (2019) as:

$$
\beta(t)=q \eta \rho_{4}\left(t-t_{e}\right) s\left[\rho_{4}\left(t-t_{E}\right)\right]+L_{0}
$$

where $q$ is the amount of viable larvae per day per sexually mature lice, which includes connectivity and larvae production rate, and $\eta$ is the proportion of female lice. $L_{0}$ is the external infection pressure and $t_{E}$ is the time it takes larvae to reinfect a host, assumed to be $5 \mathrm{~d}$ (Stien et al. 2005). $s\left[\rho_{4}(t)\right]$ is mate limitation or an Allee effect, which states that fertilisation success is close to zero at near-zero lice abundances and close to $100 \%$ at around 2 gravid lice salmon ${ }^{-1}$ (Krkošek et al. 2012, Stormoen et al. 2013, Kragesteen et al. 2019). The initial conditions are given by:

$$
\begin{gathered}
\rho_{1}(0)=0 \text { for } t=0 \\
\rho_{j+1}(t)=0 \text { for } t \leq t_{j} \text { where } j \in\{1,2,3\}
\end{gathered}
$$


where $t_{j}$ is the development time for each stage and salmon are stocked in sea cages at $t=0$.

\subsection{External infection}

The external infection pressure in this study includes, as mentioned, salmon louse larvae from other farms and from the environment or natural background infection. To calculate external infection pressure we rewrite Eqs. (2-6) by summing the pre-adult and adult stages $\left(\rho_{2}(t)+\rho_{3}(t)+\rho_{4}(t)\right)$, which corresponds to the mobile and gravid lice counts, $\rho_{m}$. Therefore:

$$
\begin{aligned}
\frac{\mathrm{d} \rho_{m}(t)}{\mathrm{d} t}= & \frac{\mathrm{d} \rho_{2}(t)}{\mathrm{d} t}+\frac{\mathrm{d} \rho_{3}(t)}{\mathrm{d} t}+\frac{\mathrm{d} \rho_{4}(t)}{\mathrm{d} t} \\
& =\beta\left(t-t_{1}\right) \mathrm{e}^{-\mu_{1} t_{1}}-\mu_{2} \rho_{2}(t)-\mu_{3} \rho_{3}(t)-\mu_{4} \rho_{4}(t)
\end{aligned}
$$

If we assume that pre-adult and adult stage mortality is $\mu_{m} \approx \mu_{2} \approx \mu_{3} \approx \mu_{4}$, then the practical implementation of this assumption is $\mu_{m}=\frac{\left(\mu_{2}+\mu_{3}+\mu_{4}\right)}{3}$, and Eq. (9) can
be written as:

$$
\frac{\mathrm{d} \rho_{m}(t)}{d t}=\beta\left(t-t_{1}\right) \mathrm{e}^{-\mu_{1} t_{1}}-\mu_{m} \rho_{m}(t)
$$

We argue that in the first $150 \mathrm{~d}$ of the production cycle there are virtually no internal dynamics, meaning we assume no internal viable larvae and/or no females are fertilised and set $q \times s$ in Eq. (6) to zero. There are 2 reasons for assuming this. First, at $11^{\circ} \mathrm{C}$ (maximum Faroese shelf water temperature), the first attached lice start releasing larvae after $\sim 50 \mathrm{~d}\left(=t_{1}+t_{2}+t_{3}\right)$ and it takes another $\sim 20 \mathrm{~d}\left(=t_{\mathrm{e}}+t_{1}\right)$ until these lice appear in the lice counts (Table 1; Stien et al. 2005). Second, due to the Allee effect, where few female lice get fertilized at low lice abundances (Krkošek et al. 2012, Stormoen et al. 2013), $s$ is close to zero. Further, gravid lice have been shown to produce fewer eggs in their first pair of egg strings (Heuch et al. 2000). With the approximation that $q \times s$ is zero, Eq. (10) can be rewritten as:

$$
\frac{\mathrm{d} \rho_{m}(t)}{\mathrm{d} t}=L_{0} \mathrm{e}^{-\mu_{1} t_{1}}-\mu_{m} \rho_{t}(t), \quad \text { for } t<150 \mathrm{~d}
$$

Table 1. Development time $(t)$ and mortality $(\mu)$ for chalimus $\left(\rho_{1}\right)$, pre-adult $\left(\rho_{2}\right)$, adult $\left(\rho_{3}\right)$ and gravid $\left(\rho_{4}\right)$ stages. Development time or stage length $t$, at $11^{\circ} \mathrm{C}, T$, is found by using the equation: $t(T)=\left[\beta_{1} /\left(T-10+\beta_{1} \beta_{2}\right)\right]^{2}$ (Stien et al. 2005), where $\beta_{1}$ and $\beta_{2}$ are shape parameters

\begin{tabular}{|lcccc|}
\hline Stage & $\beta_{1}$ & $\beta_{2}$ & $\begin{array}{c}\mu \\
\left(\mathrm{d}^{-1}\right)\end{array}$ & $\begin{array}{c}t\left[11^{\circ} \mathrm{C}\right] \\
(\mathrm{d})\end{array}$ \\
\hline$\rho_{1}$ & $74.70 \pm 33.64$ & $0.246 \pm 0.007$ & $0.002-0.01$ & $14.9\left(t_{1}\right)$ \\
$\rho_{2}$ & $67.47 \pm 20.36$ & $0.177 \pm 0.006$ & $0.025-0.18$ & $27.2\left(t_{2}\right)$ \\
$\rho_{3} \& \rho_{4}$ & $41.98 \pm 2.85$ & $0.338 \pm 0.012$ & $0.025-0.06$ & $7.6\left(t_{3}\right)$ \\
\hline
\end{tabular}

which, with the initial conditions $\left(\rho_{\mathrm{m}}\left(t_{1}\right)=0\right)$, has the analytical solution:

$$
\rho_{m}(t)=L_{0} \frac{\mathrm{e}^{-\mu_{1} t_{1}}}{\mu_{m}}\left[1-\mathrm{e}^{-\mu_{m}\left(t-t_{1}\right)}\right]
$$

for $t \geq t_{1}$. From here, the external infection pressure, $L_{0}$, may be isolated to:

$$
L_{0}=\frac{\mu_{m} \rho_{m}(t)}{\mathrm{e}^{-\mu_{1} t_{1}}\left[1-\mathrm{e}^{-\mu_{m}\left(t-t_{1}\right)}\right]}
$$

The stage duration and mortality are based on the estimates by Stien et al. (2005) (Table 1), where $\mu_{m}$ is the average of the minimum mortalities.

\subsection{Salmon-louse population growth rate}

Salmon-louse population growth rates can be calculated using Eq. (10) and dividing by $\rho_{\mathrm{m}}(t)$ :

$$
\frac{1}{\rho_{m}(t)} \frac{\mathrm{d} \rho_{m}(t)}{\mathrm{d} t}=\frac{\beta_{i}\left(t-t_{1}\right)}{\rho_{m}(t)} \mathrm{e}^{-\mu_{1} t_{1}}-\mu_{m}
$$

Writing Eq. (6) for $\beta(t)$, we get:

$$
\begin{aligned}
& \frac{\mathrm{d} \ln \left[\rho_{m}(t)\right]}{\mathrm{d} t} \\
& \quad=\left\{q \eta s\left[\rho_{4}\left(t-t_{E}-t_{1}\right)\right] \frac{\rho_{4}\left(t-t_{E}-t_{1}\right)}{\rho_{m}(t)}+\frac{L_{0}}{\rho_{m}(t)}\right\} \mathrm{e}^{-\mu_{1} t_{1}}-\mu_{m}
\end{aligned}
$$

All lice counts $150 \mathrm{~d}$ after production start are included. The growth rate is calculated by taking the log of salmon lice counts $\left(\rho_{m}(t)\right)$ and estimating the slope of a fitted line with 5 consecutive points or counts using a linear regression model (MATLAB) with random slope and intercept. Unfortunately, lice counts are affected by treatments events and/or cleaner fish. To omit these periods, we have discarded periods where the slope is negative or has an adjusted $\mathrm{R}^{2}<0.6$. See Appendix for an example of how external infection pressure and population growth rate was estimated at one farm site.

\section{RESULTS}

\subsection{Total lice}

The total number of gravid and mobile lice in the Faroese aquaculture fluctuated considerably between 2011 and 2018. The highest number of gravid and mobile lice was in December 2015, with over 35 million and 129 million, respectively (Fig. 2). The lowest number of gravid lice was below 5 million, recorded in June 2013, and the lowest for mobile lice 


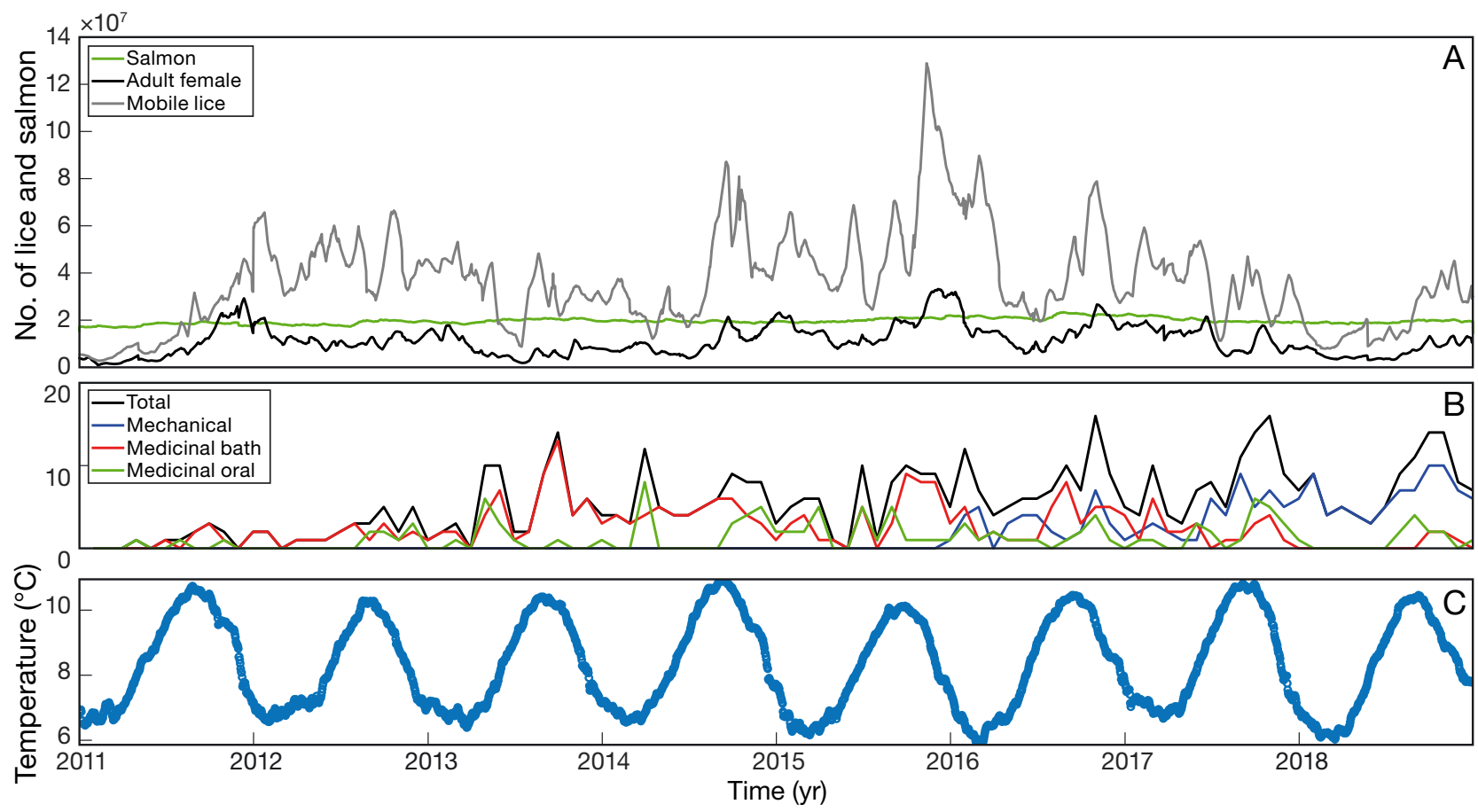

Fig. 2. (A) Total number of gravid lice, other mobile lice and salmon in the Faroe Islands. (B) Number of treatments in the Faroe Islands per month shown as total, mechanical, medicinal bath and medicinal oral treatments. (C) Faroese shelf temperature. Data are shown for the period from 2011 to 2018

was under 5 million in March 2011. The total number of gravid lice was generally below 20 million except for in the winters of 2011, 2014, 2015 and 2016. Lice numbers in 2011 may be underestimated as 6 farms were not counted regularly or at all.

The number of salmon in Faroese waters was relatively stable at around 20 million, while production increased significantly, from $50 \times 10^{3}$ t in 2011 to $71 \times$ $10^{3} \mathrm{t}$ in 2014 (www.hagstovan.fo), indicating a general increase in harvest or stocking fish size. The maximum recorded number of salmon was 23.4 million in November 2017 and the minimum was 16.8 million in February 2011 (Fig. 2A).

The number of treatments events per year steadily increased since 2011 to over 90 treatment events per year in the years 2016-2018. There was no consistent seasonal treatment pattern. Treatment type shifted from chemical to mechanical starting in 2016 and was almost exclusively mechanical in 2018 (Fig. 2B).

Average shelf sea temperature varied consistently between $10-11^{\circ} \mathrm{C}$ in September and $6^{\circ} \mathrm{C}$ in March (Fig. 2C). There was a significant correlation between temperature and total gravid and mobile lice with a lag of -95 and $-74 \mathrm{~d}$ having a correlation of 0.49 and 0.32 , respectively. In addition, a high correlation (0.95) was found between average annual gravid lice population growth rate and temperature (see Fig. 6).

Overall, the total amount of gravid and mobile lice steadily increased from 2011 to 2015, after which it steadily decreased. This is consistent with changes in regulations in 2016, where the treatment threshold was decreased from 2 to 1.5 gravid lice salmon ${ }^{-1}$ (Faroese Ministry of Foreign Affairs and Trade 2016). There was also a shift from chemical to mechanical treatments and increased treatment frequency in this period. Total lice numbers are generally lowest between May and August and highest in December and January. Number of salmon (Table 2) and average temperature in the period 2011 to 2018 remained relatively constant (Fig. 2), and therefore the total number of lice between years is likely correlated with treatment frequency and efficiency.

Table 2. Number of salmon and treatments per year, and average number of gravid and mobile lice per year in the Faroe Islands for 2011-2018

\begin{tabular}{|lccccccccc|}
\hline & 2011 & 2012 & 2013 & 2014 & 2015 & 2016 & 2017 & 2018 \\
\hline Salmon $\left(\times 10^{7}\right)$ & 1.81 & 1.87 & 1.98 & 1.94 & 2.01 & 2.16 & 2.02 & 1.92 \\
Gravid lice $\left(\times 10^{7}\right)$ & 0.97 & 1.23 & 0.83 & 1.15 & 1.78 & 1.54 & 1.26 & 0.68 \\
Mobile lice $\left(\times 10^{7}\right)$ & 1.92 & 4.93 & 3.52 & 4.10 & 5.80 & 4.81 & 3.57 & 2.03 \\
Treatments (no.) & 12 & 26 & 66 & 71 & 70 & 94 & 98 & 93 \\
\hline
\end{tabular}




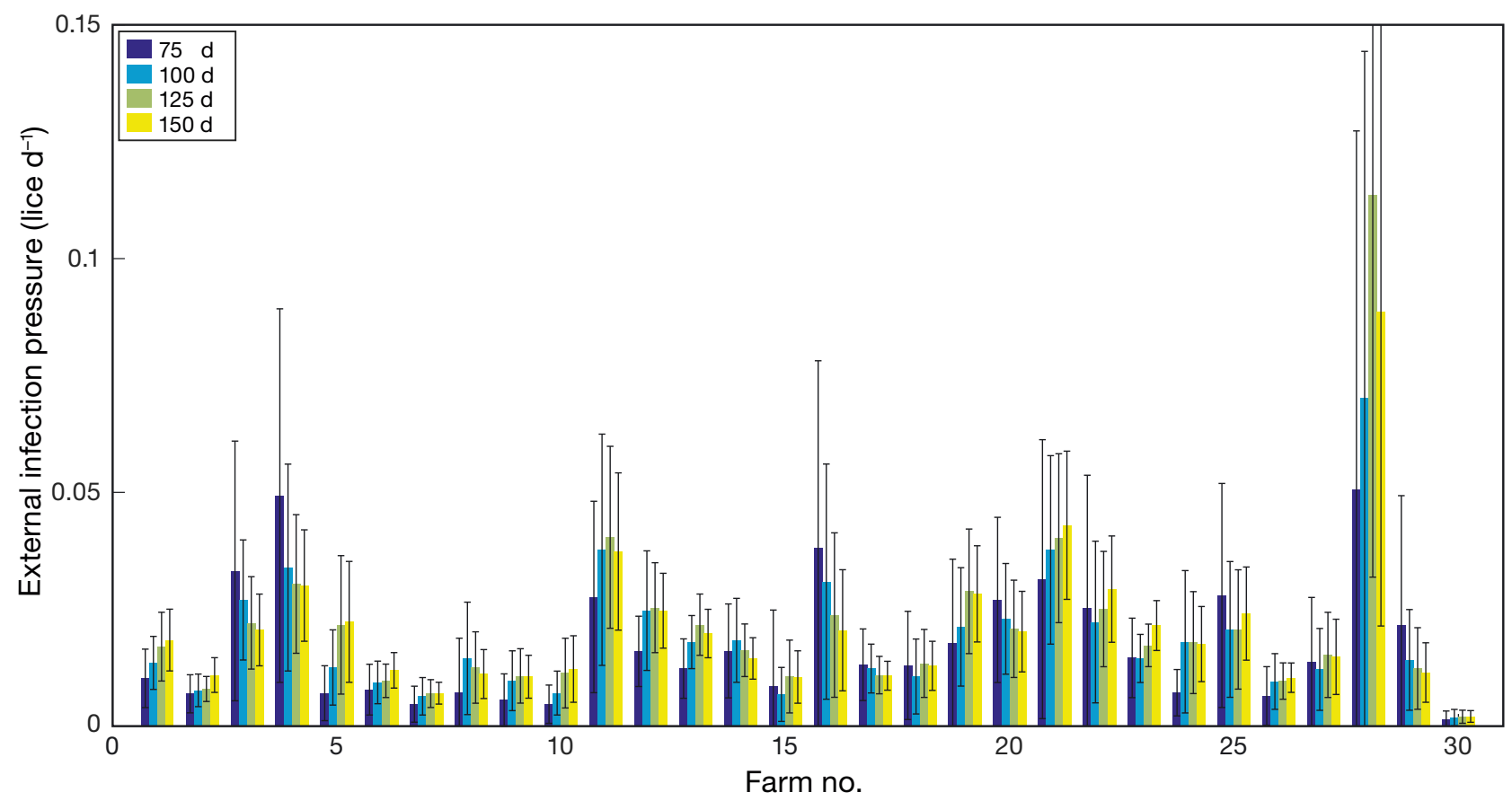

Fig. 3. Average external infection pressure including the first 75, 100, 125 and 150 d, with $95 \%$ CI error bars for each farm site in the Faroe Islands $(\mathrm{n}=30)$

\subsection{External infection pressure}

Based on all lice counts in the first $150 \mathrm{~d}$ in all production cycles at each farm from 2011 to 2018, the external infection pressure is estimated on average to range from 0.002 to 0.1 lice salmon ${ }^{-1} \mathrm{~d}^{-1}$ (Fig. 3). Farm 28 is an outlier and had the highest average external infection pressure; however, this estimate was based on only one production cycle in 2015. Farm 30 clearly had the lowest average external infection pressure, with 0.002 lice salmon ${ }^{-1} \mathrm{~d}^{-1}$. In addition to the period of no internal dynamics of $150 \mathrm{~d}$ (discussed in section 2.6), the external infection pressure was estimated using periods of 75, 100 and $125 \mathrm{~d}$. For many farms, the external infection pressure increased with number of days included, while for other farms it decreased, and for a few farms external infection pressure stayed constant, but generally the effect was not significant (Fig. 3).

In highly connected farm networks such as the Faroe Islands (Kragesteen et al. 2018), we expected external infection pressure to increase with the total amount of gravid lice within the farm network. Therefore, the relationship between external infection pressure and the total number of gravid lice was investigated by performing a linear regression model fit with a random slope and an intercept for the estimated external infection pressure as a function of the total gravid lice (MATLAB 2020). The mean level of gravid lice was estimated 15 to $45 \mathrm{~d}$ prior to each lice count. The results show that an increase in the total number of gravid lice significantly increased the external infection pressure $\left(F_{29,844}=12.7, \mathrm{p}<0.001\right)$; however, the $\mathrm{R}^{2}$ was low $(0.312)$, indicating that total number of gravid lice does not explain the variability well (Fig. 4). In addition, for the majority of farms, external infection pressure increased roughly from 0.001 to 0.004 lice salmon ${ }^{-1} \mathrm{~d}^{-1}$ for every million gravid lice in the farm network (Fig. 4). Farm 30 is an exception, having a significant lower external infection pressure, likely due to its isolated location.

\subsection{Population growth rate}

Growth rates of number of lice per salmon were estimated to be between 1.7 and $5.4 \% \mathrm{~d}^{-1}$ on average for all farms (Fig. 5). These estimates are slightly higher but comparable to that found in Patursson et al. (2017) and Krkošek et al. (2010). The estimated growth rates do not separate between internal and external dynamics (Eq. 15); however, we expected that farms with high internal infection pressure would have a higher growth rate as opposed to farms driven by external infection pressure (See Eq. 15). For example, farms 4, 23 and 24 all had relatively low population growth rates, which was as expected because they are located in areas with high ventilation due to the 

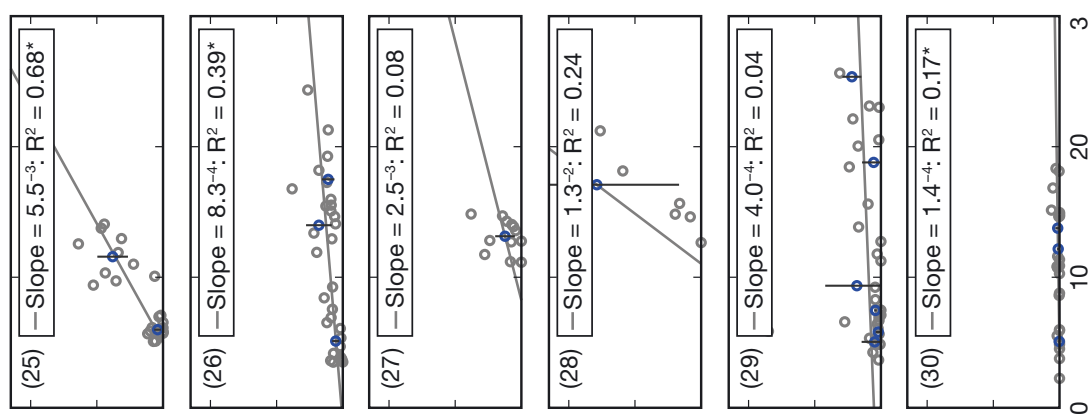

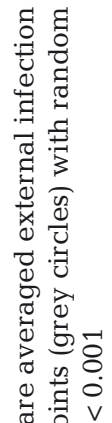
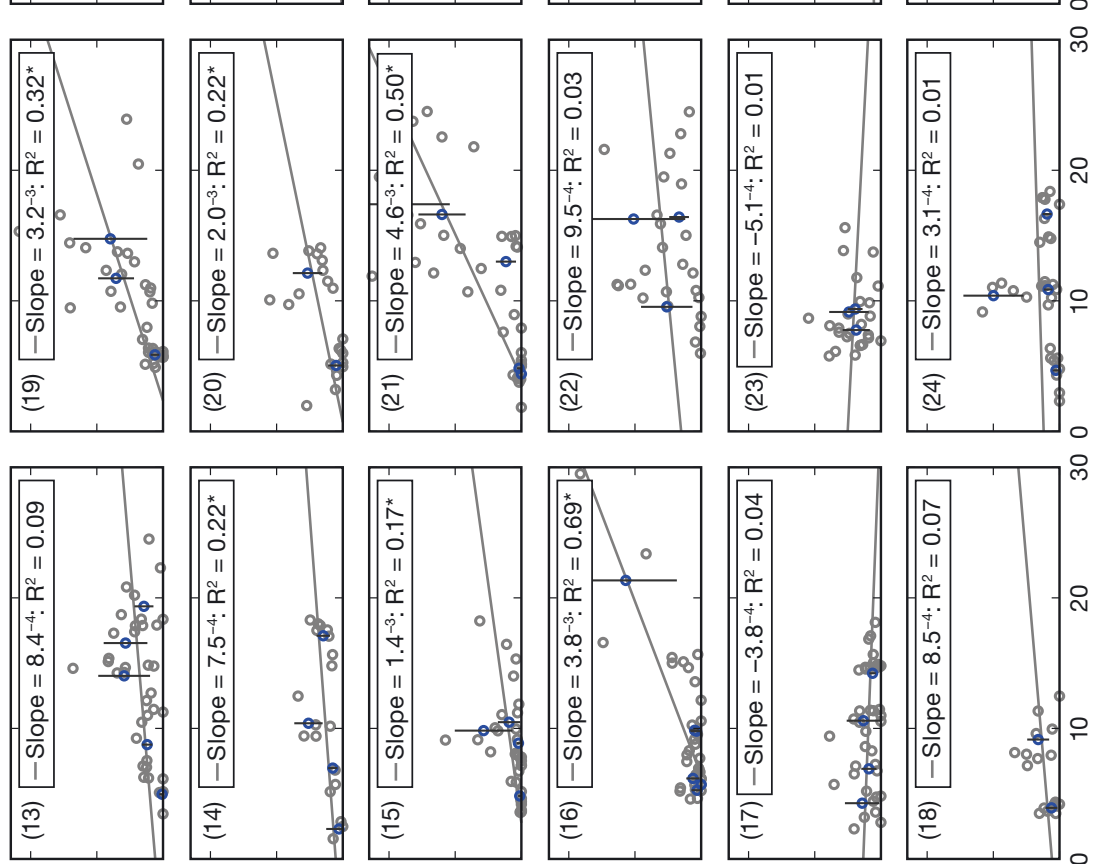

$\left.\right|_{0} ^{\infty} \frac{8}{\frac{0}{x}}$
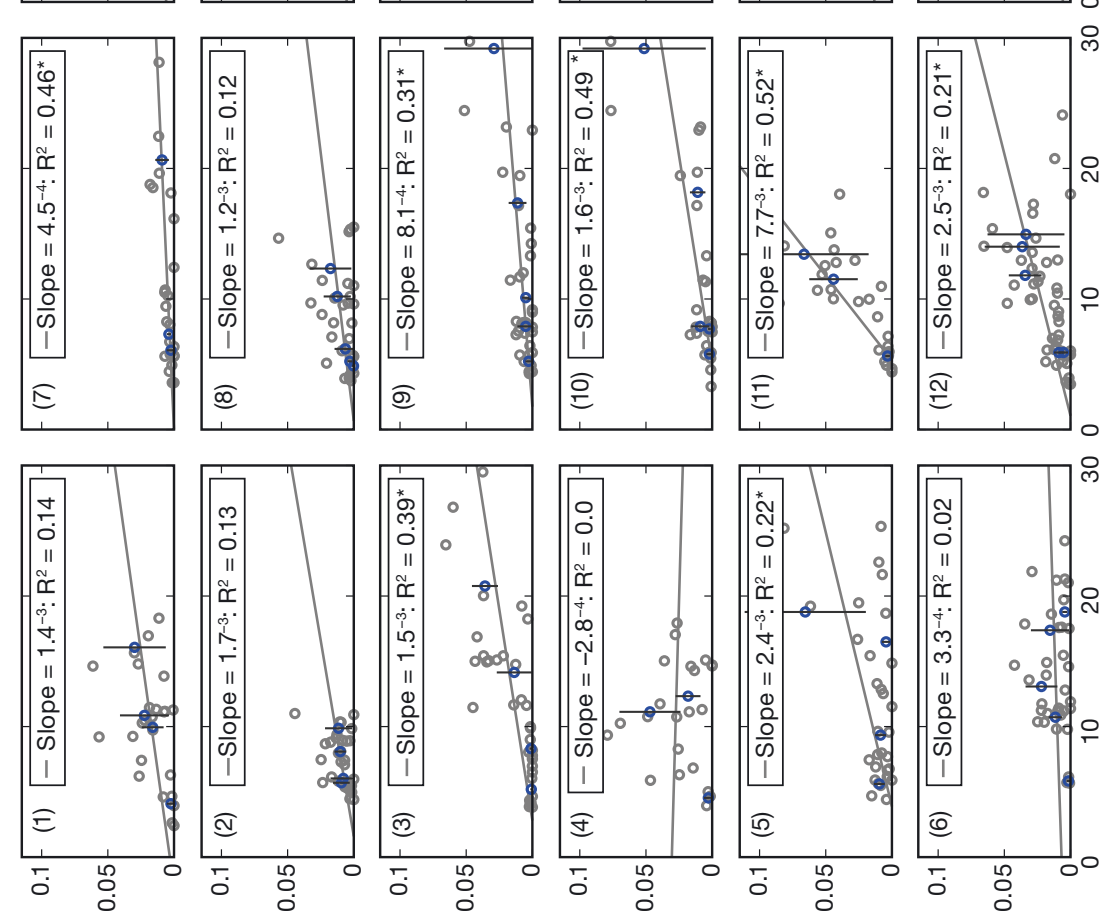

o 20

氙营

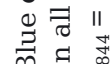

공ำ

官造圷

II $\vec{d}$

द्व

ज结

콩

헝

○

$\times \quad 2:-\frac{1}{8}$

.0

응

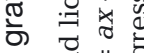

ब

s.

ป

苟造

वृ

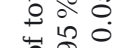

동

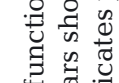

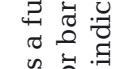

वै

중

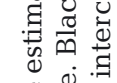

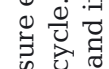

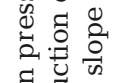

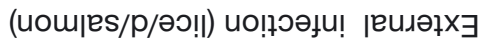

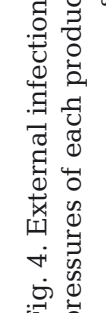




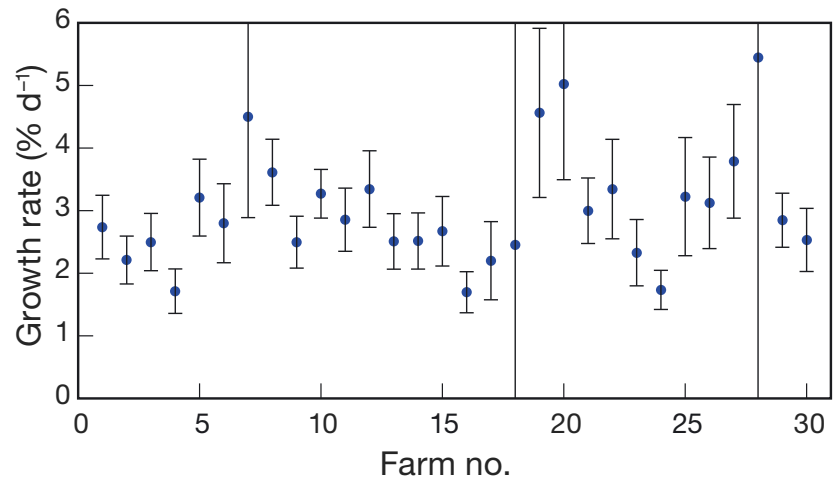

Fig. 5. Average salmon-louse population growth rate for each farm site in the Faroe Islands with $95 \%$ CI

tidal currents. Farm 28 showed the highest measured growth rate, likely because the growth rate was based on only 1 production cycle between the years 2015 and 2016, where the total number of gravid lice also was high and/or the growth rate was positively influenced by treatment events, as population growth rate is typically high for a period immediately following a treatment (Kragesteen et al. 2019).

We also explored the average annual population growth rate of the total number of gravid lice in the Faroe Islands from 2011 to 2018 (Fig. 6). This was done by calculating daily population growth rate by log transforming the total number of gravid lice (Eq. 14) and finding the slope of a straight line fitted with 14 and 90 consecutive days. Each calculated growth rate was sorted into day of year and averaged between all years. Average population growth rate was negative for approximately the first 160-170 d of the year, after which the average growth rate turned positive until approximately Day 350 of the year where the average growth rate again turned negative. The average annual lice population growth rate over $90 \mathrm{~d}$ was highly correlated (0.95) with average annual temperature. The average annual lice population growth rate over $14 \mathrm{~d}$ oscillates consistently and no clear correlation with temperature was found.

\section{DISCUSSION}

From an extensive time-series of lice counts, we show how salmon-louse numbers have developed in Faroese aquaculture from 2011 to 2018. Further, the average external infection pressure and salmonlouse population growth rate for each active farm site from 2009-2018 was estimated. External infection pressure varied greatly between farms (Fig. 3), which was expected due to differences in hydrodynamic conditions (Patursson et al. 2017) and connectivity between farm sites (Kragesteen et al. 2018). The external infection pressure within farms depended on the total amount of gravid lice present in the farm network (Fig. 4).

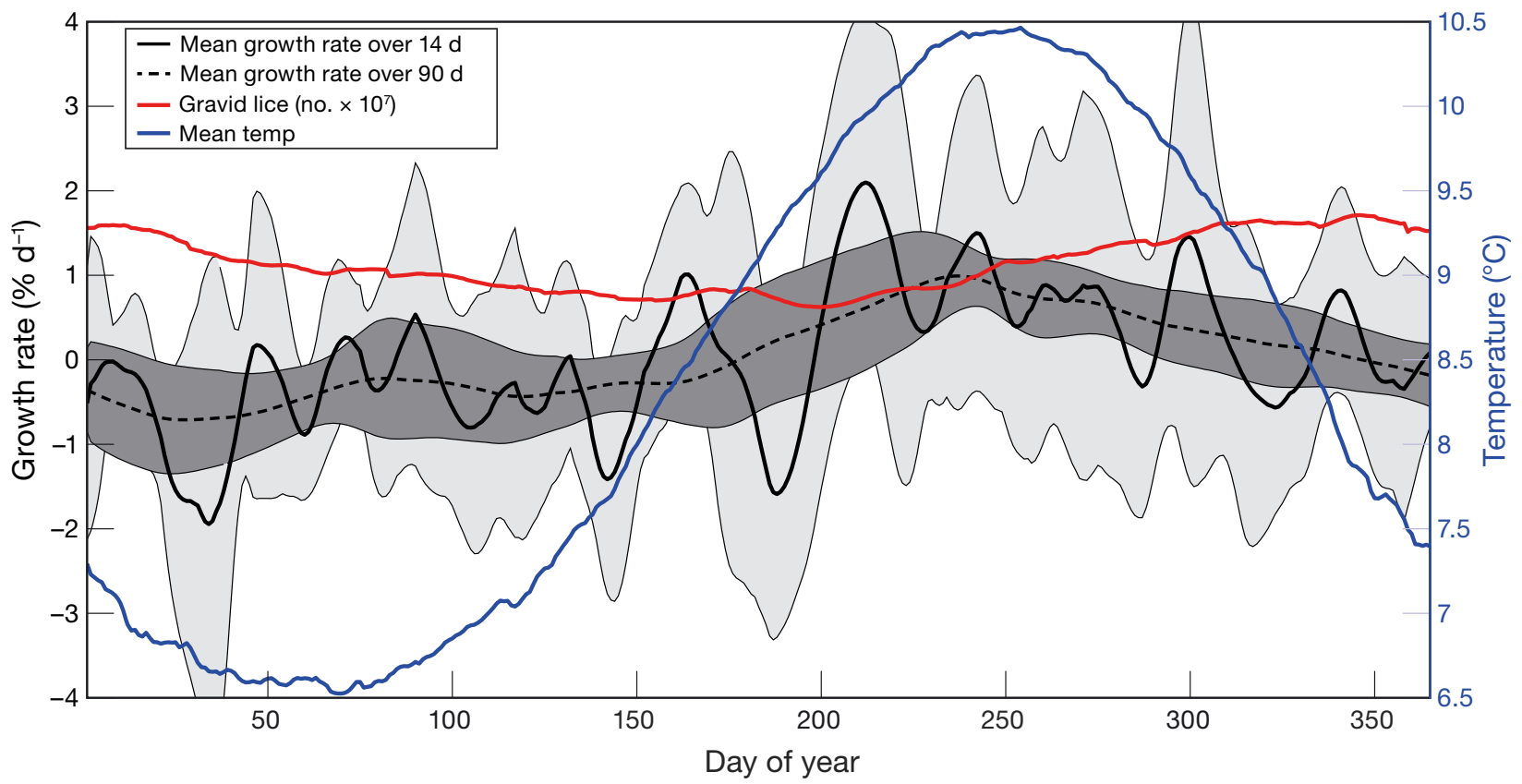

Fig. 6. Daily salmon-louse population growth rate of total Faroese gravid lice plotted by day of year averaged over $14 \mathrm{~d}$ and 90 d from 2011 to 2018, and total number of gravid lice. Light grey and dark grey shading indicate 95\% CI for population growth rate averaged over 14 and 90 d, respectively. Daily annual temperature averaged for 2011 to 2018 is also shown 
The total number of gravid and mobile lice in the Faroe Islands was significantly higher compared to a similar salmon aquaculture area (15-18 million salmon) off the coast of mid-Norway (Jevne \& Reitan 2019). This coastal area has 18 farm sites located between a group of islands and has a water temperature range similar to that of the Faroe Islands. One difference is that this Norwegian aquaculture region has synchronised production cycles and the level of salmon lice is therefore effectively reset between each cycle. Comparing the number of treatments between these 2 areas is not straightforward, as treatments are reported differently (number of cages treated in Norway and number of treatment events in the Faroe Islands). However, if we assume that a treatment event on average represents 5 treated cages, then about 450 cages were treated per year $(90 \times 5)$ in the Faroe Islands in the period from 2016 to 2018 (Table 2). Jevne \& Reitan (2019) reported 262, 550 and 102 cages being treated in production cycles 1, 2 and 3, respectively, where a production cycle is almost 2 yr long. Production cycle 2 had the highest levels of lice and also the highest number of cages treated, but this is still a factor of 2 lower than the Faroe Islands. A reason for the higher treatment frequency in the Faroe Islands may be the overlapping production in contrast to synchronised production in the Norwegian area. This would contradict claims that coordinated fallowing is ineffective (Guarracino et al. 2018). Another reason could be the relatively low treatment threshold of 0.2 to 0.5 gravid lice salmon ${ }^{-1}$ in Norway (Nærings- og fiskeridepartementet 2012) in contrast to 1.5 to 2 gravid lice salmon ${ }^{-1}$ in the Faroe Islands, which may seem counter-intuitive. However, farms in Norway are forced to treat early to keep lice levels relatively low and thereby earn the benefit of the Allee effect, resulting in an overall lower larvae production rate and, consequently, a lower lice population growth rate (Krkošek et al. 2012, Stormoen et al. 2013, Kragesteen et al. 2019). A third reason is that there is a mean current flow through the Norwegian area, and therefore lice may be less retained in contrast to the Faroe Islands, where shelf water is relatively retained (Kragesteen et al. 2018). Last, we currently have insufficient data for cleaner fish, which may be more widely used in the Norwegian island group, resulting in fewer treatments.

Salmon-louse levels were typically highest in December-January (Fig. 2). This is likely due to the salmon-louse population growth rate in the Faroe Islands being positive until approximately $90 \mathrm{~d}$ after the highest recorded sea temperature (September). The highest lice abundance was observed shortly before the net growth rate turned negative (Fig. 6).
We also speculate that chlorophyll concentration could be a good indicator of lice population growth rate and lice levels, because high levels of chlorophyll will subsequently lead to high levels of zooplankton, which may lead to a higher mortality of planktonic lice larvae. However, we found no clear correlation, possibly due to chlorophyll and zooplankton being out of phase or because the chlorophyll samples were from a single location and thus not representative of the general chlorophyll concentration in the Faroe Islands.

If the external infection pressure estimates from the earlier-mentioned studies are converted to lice salmon $^{-1} \mathrm{~d}^{-1}$ using Eq. (2), we find up to 0.17 (Bjørn et al. 2011), 1.16 (Sandvik et al. 2016), 2.16 (Pert et al. 2014) and 0.001 lice salmon ${ }^{-1} \mathrm{~d}^{-1}$ (Karbowski et al. 2019), when minimum mortality of the chalimus stage is assumed (Table 1). The external infection pressure estimates in the present study are therefore considerably lower compared to the sentinel cage estimates in Norway and Scotland (Bjørn et al. 2011, Pert et al. 2014, Sandvik et al. 2016) and slightly higher than estimates from Iceland in a fjord containing only 2 salmon farms (Karbowski et al. 2019). One reason for the observed difference could be the dilution effect reported by Samsing et al. (2014): because there are relatively few salmon in the sentinel cages, there are potentially many more lice per salmon compared to a fully operational high salmon density farm cage. External infection pressure estimates from sentinel cages may, as a result, be much higher compared to our estimates. This dilution effect should be investigated further.

External infection pressure was estimated based on the first $150 \mathrm{~d}$ of a production cycle, as we assumed the effects of salmon-louse internal dynamics to be low or non-existent in this period. This assumption can be debated in particular when water temperature is high (i.e. $>11^{\circ} \mathrm{C}$ ). If internal dynamics are significant in this period, there will be an overestimation of the external infection pressure. However, the difference between including the first 75, 100, 125 and 150 d does not significantly affect the average estimated external infection pressure (Fig. 3). An explanation for increasing external infection pressure could be that the internal dynamics start before the Day 150, which would cause the estimated external infection pressure to increase with time. Another explanation could be the increased surface area of salmon, e.g. if a salmon weighs $200 \mathrm{~g}$ when put out to sea, it will increase its weight to about $900 \mathrm{~g}$ during the first $150 \mathrm{~d}$ (Austreng et al. 1987). This increase in 
weight will increase the salmon surface area from approximately 335 to $810 \mathrm{~cm}^{2}$ (O'Shea et al. 2006). Consequently, infectious lice larvae will have 2.4 times more area to attach onto $150 \mathrm{~d}$ after sea stocking. Therefore, external infection pressure should be standardised with salmon size; however, these data were not available. A problem with the external infection pressure estimates is that treatments do occur in the first $150 \mathrm{~d}$ period, and many farms, especially after 2015, had cleaner fish present in their sea cages. This may have led to an underestimation of the external infection parameter $L_{0}$ and may have caused the external infection pressure to decrease in the $150 \mathrm{~d}$ period. In summary, the external infection pressure estimates are uncertain. Nevertheless, these estimates have a high applied value as they are based on in situ lice counts from commercial farms reflecting the actual infection pressure at an operational salmon farm.

Here, we do not distinguish between external infection pressure caused by larvae production from neighbouring farms and the natural background infection from wild salmonid stocks. There is a small wild salmon stock that was introduced and has been maintained since the 1940s in 4 Faroese rivers (www. laks.fo). The population size and level of infection of other salmon-louse hosts such as sea trout and Arctic charr are unknown. In Norway, the wild salmon stock is estimated to be about 550000 fish (Norwegian Institute for Nature Research 2019), and the Faroese wild stock is likely only a small fraction of this; consequently, the ratio between the wild stock and the 20 million salmon in the cages is likely small, and therefore it seems reasonable to assume that the infection load from the wild salmonids is low. As a result, external infection should predominately be determined by the total number of gravid lice in Faroese salmon farms. Our study shows a significant but low $\mathrm{R}^{2}$, although this was highly variable between farms (Fig. 4). The reason for the relatively low correlation could be the stochastic nature of the lice count procedure, where only 10 fish per cage were counted. In addition, treatments and cleaner fish will also negatively influence the correlation. Further, some farms may be strongly connected to only a few farms, and therefore the total amount of Faroese gravid lice may not be representative of the external pressure at these farms (Kragesteen et al. 2018).

The principles of measuring salmon-louse population growth rates are relatively simple as we assumed exponential growth (Eq. 15) and fitted a straight line with a number of consecutive log-transformed lice counts. Here we decreased the effects of treatments by excluding negative growth rates and poorly correlated data $\left(\mathrm{R}^{2}<0.6\right.$; Fig. A1C). This approach differs from that of Patursson et al. (2017), as we considered all lice counts after $150 \mathrm{~d}$ into a production cycle, whereas Patursson et al. (2017) discarded an initial period until the first treatment occurred. Population growth rates include both internal and, external dynamics, and at low lice abundances, external dynamics are more dominant $\left(\frac{L_{0} \mathrm{e}^{-\mu_{1} t_{1}}}{\rho_{m}(t)}\right)$, while at higher lice abundances, the internal dynamics will dominate the growth rate due to both decreased contribution of external dynamics and a low or absent Allee effect. A problem with this method is that the population growth rate is very high immediately after a treatment event, and may lead to an overestimation of the growth rate. Nevertheless, we estimated the growth rate for each production cycle and each active farm site with a relatively high number of growth rate estimates, which makes the estimates altogether robust and illustrates the variability among farm sites.

\section{CONCLUSION}

In conclusion, our results provide estimates of vital salmon-louse population dynamic parameters based on biweekly monitoring lice counts. External infection was found to vary between farm sites from 0.002 to 0.1 lice salmon ${ }^{-1} \mathrm{~d}^{-1}$ (Fig. 3). Because of the likely small ratio between wild and farmed salmon, we believe there is a negligible contribution from wild salmonid stocks on external infection pressure compared to the infection within the Faroese farm network. We show an overall significant relationship between external infection pressure and total number of gravid lice, which generally increased from 0.001 to 0.004 lice salmon ${ }^{-1} \mathrm{~d}^{-1}$ for every million gravid lice (Fig. 4). The salmon-louse population growth rate was found to vary between farms, ranging from 1.7 to $5.4 \% \mathrm{~d}^{-1}$ (Fig. 6). These growth rates are comparable to other estimates (Krkošek et al. 2010, Patursson et al. 2017).

The estimated parameters can be used to fit a salmon-louse population dynamic model, allowing for robust predictions of salmon-louse development on a per-farm basis. Further, such estimates can be used to calibrate and validate a bio-economic lice model (Kragesteen et al. 2019) forced by connectivity between farms based on hydrodynamic modelling, which could substantially improve lice management by identifying the most cost-effective approach. 
Acknowledgements. This study was financially supported by Danmarks Innovationsfond (grant no. 5189-00032A) and by Granskingarráðið - Research Council Faroe Islands (grant no. 0450). We thank the companies Bakkafrost, Luna and Mowi (Marine Harvest) for supplying data. Thanks also go to Ása Johannesen for help with statistical analysis, Trøndur T. Johannesen for help with the mathematics and Gunnvør á Noròi for scientific input. Constructive comments from the 3 anonymous reviewers are very much appreciated.

\section{LITERATURE CITED}

Adams T, Proud R, Black KD (2015) Connected networks of sea lice populations: dynamics and implications for control. Aquacult Environ Interact 6:273-284

Anderson RM, May RM (1979) Population biology of infectious diseases: Part I. Nature 280:361-367

* Austreng E, Storebakken T, Åsgård T (1987) Growth rate estimates for cultured Atlantic salmon and rainbow trout. Aquaculture 60:157-160

* Bjørn PA, Sivertsgård R, Finstad B, Nilsen R, Serra-Llinares RM, Kristoffersen R (2011) Area protection may reduce salmon louse infection risk to wild salmonids. Aquacult Environ Interact 1:233-244

Boxaspen K (2006) A review of the biology and genetics of sea lice. ICES J Mar Sci 63:1304-1316

Faroese Ministry of Foreign Affairs and Trade (2016) Kunnger um yvirtøku of tálming av lúsum á alifiski, kg. 75, 28 nov. 2016. https://logir.fo/Kunngerd/75-fra-28-06-2016um-yvirvoku-og-talming-av-lusum-a-alifiski (accessed 16 Nov 2020)

Frazer LN, Morton A, Krkošek M (2012) Critical thresholds in sea lice epidemics: evidence, sensitivity and subcritical estimation. Proc R Soc B 279:1950-1958

* Gettinby G, Robbins C, Lees F, Heuch PA, Finstad B, Malkenes R, Revie CW (2011) Use of a mathematical model to describe the epidemiology of Lepeophtheirus salmonis on farmed Atlantic salmon Salmo salar in the Hardangerfjord, Norway. Aquaculture 320:164-170

* Guarracino M, Qviller L, Lillehaug A (2018) Evaluation of aquaculture management zones as a control measure for salmon lice in Norway. Dis Aquat Org 130:1-9

*Hamre LA, Eichner C, Caipang CMA, Dalvin ST and others (2013) The salmon louse Lepeophtheirus salmonis (Copepoda: Caligidae) life cycle has only two chalimus stages. PLOS ONE 8:e73539

Heuch P, Nordhagen J, Schram T (2000) Egg production in the salmon louse [Lepeophtheirus salmonis (Krøyer)] in relation to origin and water temperature. Aquacult Res 31:805-814

Jevne LS, Reitan KI (2019) How are the salmon lice (Lepeophtheirus salmonis Krøyer, 1837) in Atlantic salmon farming affected by different control efforts: a case study of an intensive production area with coordinated production cycles and changing delousing practices in 20132018. J Fish Dis 42:1573-1586

Karbowski CM, Finstad B, Karbowski N, Hedger RD (2019) Sea lice in Iceland: assessing the status and current implications for aquaculture and wild salmonids. Aquacult Environ Interact 11:149-160

Kragesteen TJ, Simonsen K, Visser AW, Andersen KH (2018) Identifying salmon lice transmission characteristics between Faroese salmon farms. Aquacult Environ Interact 10:49-60
Kragesteen TJ, Simonsen K, Visser AW, Andersen KH (2019) Optimal salmon lice treatment threshold and tragedy of the commons in salmon farm networks. Aquaculture 512: 734329

Kristoffersen AB, Jimenez D, Viljugrein H, Grøntvedt R, Stien A, Jansen PA (2014) Large scale modelling of salmon lice (Lepeophtheirus salmonis) infection pressure based on lice monitoring data from Norwegian salmonid farms. Epidemics 9:31-39

Kristoffersen AB, Qviller L, Helgesen KO, Vollset KW, Viljugrein H, Jansen PA (2018) Quantitative risk assessment of salmon louse-induced mortality of seaward-migrating post-smolt Atlantic salmon. Epidemics 23:19-33

Krkošek M, Lewis MA, Volpe JP, Morton A (2006) Fish farms and sea lice infestations of wild juvenile salmon in the Broughton Archipelago - a rebuttal to Brooks (2005). Rev Fish Sci 14:1-11

Krkošek M, Bateman A, Proboszcz S, Orr C (2010) Dynamics of outbreak and control of salmon lice on two salmon farms in the Broughton Archipelago, British Columbia. Aquacult Environ Interact 1:137-146

Krkošek M, Connors BM, Lewis MA, Poulin R (2012) Allee effects may slow the spread of parasites in a coastal marine ecosystem. Am Nat 179:401-412

Nærings- og fiskeridepartementet (2012) Forskrift om bekjempelse av lakselus i akvakulturanlegg. https://lovdata. no/dokument/SF/forskrift/2012-12-05-1140 (accessed 16 Nov 2020)

Norwegian Institute for Nature Research (2019) Status for norske laksebestander i 2018. http://hdl.handle.net/ 11250/2503390 (accessed 16 Nov 2020)

* O'Shea B, Mordue-Luntz A, Fryer R, Pert C, Bricknell I (2006) Determination of the surface area of a fish. J Fish Dis 29:437-440

*Patursson EJ, Simonsen K, Visser AW, Patursson Ø (2017) Effect of exposure on salmon lice Lepeophtheirus salmonis population dynamics in Faroese salmon farms. Aquacult Environ Interact 9:33-43

* Pert CC, Fryer RJ, Cook P, Kilburn R and others (2014) Using sentinel cages to estimate infestation pressure on salmonids from sea lice in Loch Shieldaig, Scotland. Aquacult Environ Interact 5:49-59

* Pike AW, Wadsworth SL (1999) Sealice on salmonids: their biology and control. Adv Parasitol 44:233-337

* Revie CW, Robbins C, Gettinby G, Kelly L, Treasurer J (2005) A mathematical model of the growth of sea lice, Lepeophtheirus salmonis, populations on farmed Atlantic salmon, Salmo salar L., in Scotland and its use in the assessment of treatment strategies. J Fish Dis 28: 603-613

Robbins C, Gettinby G, Lees F, Baillie M, Wallace C, Revie CW (2010) Assessing topical treatment interventions on Scottish salmon farms using a sea lice (Lepeophtheirus salmonis) population model. Aquaculture 306:191-197

* Samsing F, Oppedal F, Johansson D, Bui S, Dempster T (2014) High host densities dilute sea lice Lepeophtheirus salmonis loads on individual Atlantic salmon, but do not reduce lice infection success. Aquacult Environ Interact 6:81-89

* Sandvik AD, Bjørn PA, Ådlandsvik B, Asplin L and others (2016) Toward a model-based prediction system for salmon lice infestation pressure. Aquacult Environ Interact 8:527-542

Schram TA (1993) Supplementary descriptions of the developmental stages of Lepeophtheirus salmonis (Krøyer, 
1837) (Copepoda: Caligidae). In: Boxshall GA, Defaye D (eds) Pathogens of wild and farmed fish: sea lice. CRC Press, Boca Raton, FL, p 30-47

Stien A, Bjørn PA, Heuch PA, Elston DA (2005) Population dynamics of salmon lice Lepeophtheirus salmonis on
Atlantic salmon and sea trout. Mar Ecol Prog Ser 290: 263-275

Stormoen M, Skjerve E, Aunsmo A (2013) Modelling salmon lice, Lepeophtheirus salmonis, reproduction on farmed Atlantic salmon, Salmo salar L. J Fish Dis 36:25-33

\section{Appendix.}

External infection pressure and salmon-louse population growth rate were estimated for each active Faroese farm site and each production cycle in the period from 2011 to 2018. The calculation is exemplified with Fig. A1. External infection $\left(L_{0}\right)$ pressure was estimated for each lice count performed over the first $150 \mathrm{~d}$ after sea stocking (Fig. A1B) using Eq. (13). For example, the third lice count at $58 \mathrm{~d}$ after sea stocking has 0.45 gravid lice salmon ${ }^{-1}$ and 1.25 mobile lice salmon ${ }^{-1}$, where the mean sea temperature the previous $30 \mathrm{~d}$ was $10.4^{\circ} \mathrm{C}$ (Fig. A1A). We find that $t_{1}\left(10.4^{\circ} \mathrm{C}\right)=14.8 \mathrm{~d}$, using the equation $t_{1}(T)=\left[\beta_{1} /\left(T-10+\beta_{1} \beta_{2}\right)\right]^{2}$ (Stien et al. 2015). See also Table 1. When calculating $L_{0}$, we use Eq. (13) to arrive at:

$$
L_{0}=\frac{0.025 \mathrm{~d}^{-1}\left(0.45+1.25 \text { lice salmon }^{-1}\right)}{\mathrm{e}^{-0.002 d^{-1} \cdot 14.8 d}\left(1-\mathrm{e}^{-0.025 \mathrm{~d}^{-1}(58 \mathrm{~d}-14.8 \mathrm{~d})}\right)}=0.066 \text { lice salmon }^{-1} \mathrm{~d}^{-1}
$$

Using this calculation for all lice counts for the first $150 \mathrm{~d}$, we obtain a mean $L_{0}$ of 0.006 lice salmon ${ }^{-1} \mathrm{~d}^{-1}$.

The salmon-louse population growth rate (Eq. 15) was estimated by fitting a straight line between 5 consecutive lice counts $150 \mathrm{~d}$ after sea stocking and excluding all lines with a negative slope and/or $\mathrm{R}^{2}<0.6$ (Fig. A1C). Using the salmonlouse population model (Eqs. 2-6) to simulate population growth, we found that the growth rate was relatively high for a short period after a treatment, because a treatment only kills attached stages and, therefore, all larvae produced before a treatment can re-infect the farm site, resulting in a higher percentage growth.

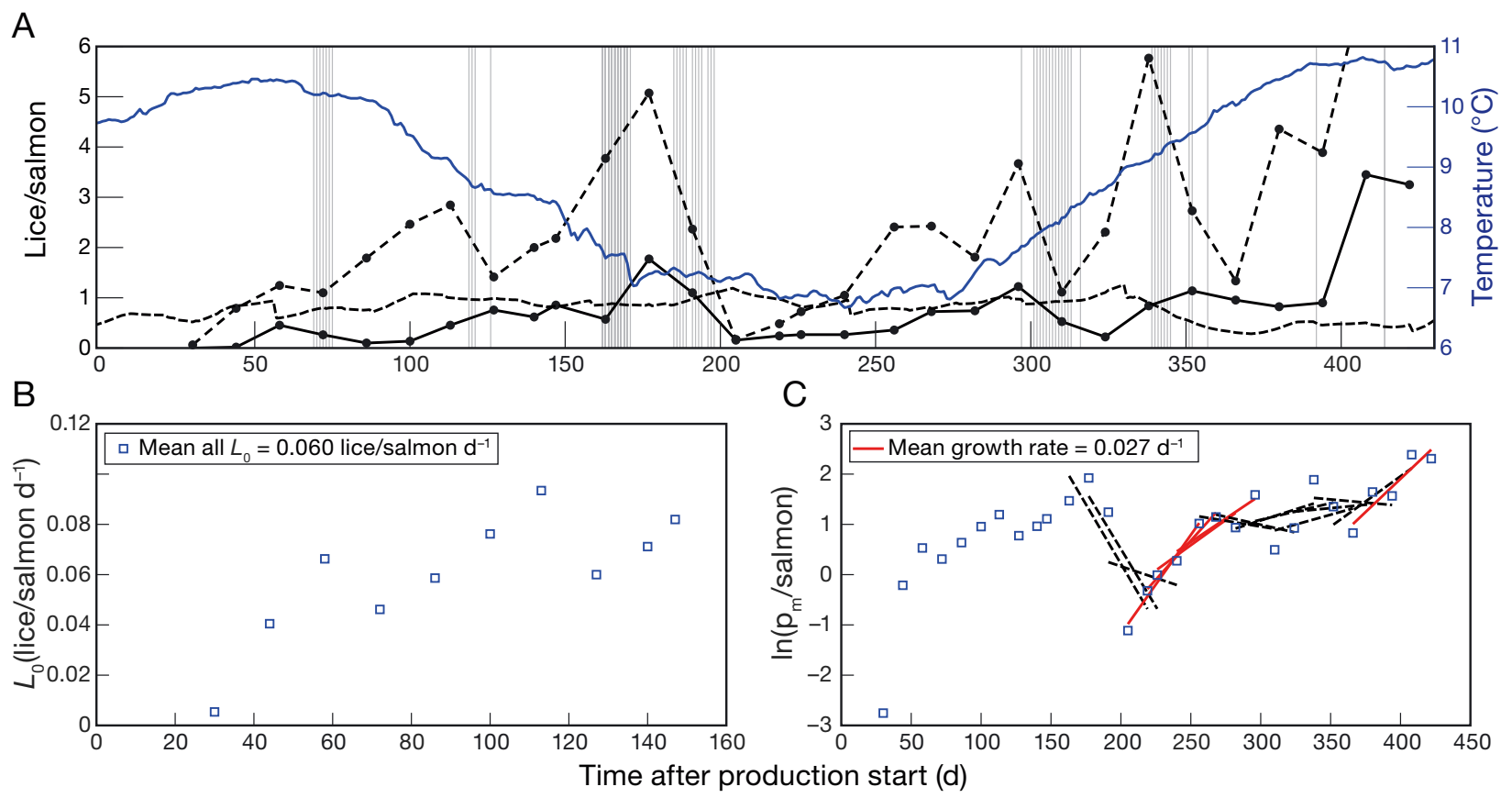

Fig. A1. Example of the calculation of external infection pressure and population growth rate. (A) Gravid and mobile lice shown as solid and dashed lines, respectively. Dashed-dotted line is the mean gravid lice salmon ${ }^{-1}$ in farm network. Vertical lines indicate treatment events and the blue line is temperature. (B) External infection pressure, $L_{0}$, calculated for lice counts before $150 \mathrm{~d}$ after sea stocking. (C) Natural log of $\rho_{\mathrm{m}}$, where lines are fitted with 5 consecutive lice counts $150 \mathrm{~d}$ after sea stocking. Red lines indicate positive slope and $\mathrm{R}^{2}>0.6$. The mean slope of the red lines in this example is calculated to be $0.27 \mathrm{~d}^{-1}$. Black dashed lines indicate negative slopes or $\mathrm{R}^{2}<0.6$

Editorial responsibility: Bengt Finstad, Trondheim, Norway
Submitted: May 29, 2020; Accepted: November 18, 2020 Proofs received from author(s): January 20, 2021 